\title{
Passos para uma convergência de duas teorias dialógicas do self
}

\author{
Mariela Michela ${ }^{*}$ \\ Fernando Andacht ${ }^{\mathrm{b}}$ \\ ${ }^{a}$ Diplomatura Psicoterapia en Servicios de Salud, Universidad de la República, Montevideo, Uruguai \\ ${ }^{b}$ Departamento de Teoría y Metodología, Facultad de Información y Comunicación Universidad de la República, Montevideo, Uruguai
}

Resumo: Neste artigo, nosso intuito é descrever os elementos que permitiriam aos pesquisadores reunir duas teorias diferentes, porém complementárias do self no campo da psicologia dialógica: a teoria do self semiótico - baseada no modelo triádico da geração de sentido de C. S. Peirce - e a teoria do self dialógico, baseada nos trabalhos de H. Hermans, os quais derivam das ideias do dialogismo de M. Bakhtin e de W. James. A vantagem dessa convergência teórica é argumentada através da apresentação dos componentes estruturais da semiótica triádica, incluída sua base fenomenológica e sua afinidade com os conceitos centrais da teoria do self dialógico. Discutimos um caso no qual o diálogo interno de uma pessoa com uma dúvida importante sobre sua vida é observado através de um método psicodramático, e assim a convergência teórica proposta é ilustrada através da manifestação de posições do eu opostas. Observou-se durante o decorrer do diálogo uma tentativa de síntese através da emergência de uma metaposição.

Palavras-chave: self semiótico, self dialógico, convergência teórica, diálogo interno.

Nas últimas décadas, o conceito de self ou si mesmo vem sendo abordado em duas perspectivas diferentes e opostas. Por um lado, concepções do self como produtos de uma construção da mente e, por outro, teorias que procuram as bases biológicas dos atributos psicológicos. Praetorius (2003) distingue duas grandes linhas teóricas dominantes na psicologia: de um lado, o construtivismo e o construcionismo social, e de outro, o naturalismo, associado a teorias cognitivistas, tais como a neurociência cognitiva. Embora o objetivo das teorias psicológicas contemporâneas tenha sido fugir do dualismo tradicional, as tentativas só têm conseguido, conforme a autora, hierarquizar um dos termos da oposição mente/matéria em detrimento do outro. Assim, o dualismo continua vigente em teorias inconciliáveis que terminam por reproduzir, em vez de resolver, o problema que elas abordam. Segundo Praetorius (2003), uma alternativa ao dualismo só poderia ser encontrada uma vez refutada a hipótese de que um domínio prescinde do outro.

Held (2007) descreve um esforço teórico recente de reconciliação de opostos pelo apelo à moderação e à exploração de convergências para construir na psicologia teorias que adotem uma posição de compromisso que permitam, sem propor um self autoritário e infalível, recuperar a agentividade do sujeito. Nesse movimento teórico inscreve-se o denominado "giro interpretativo", o qual está baseado em princípios que a autora descreve como "realismo pós-positivista".

Na sua tese doutoral, Souza (2005) destaca duas perspectivas teóricas na psicologia, que tentam responder aos problemas epistemológicos ocasionados pelo etnocentrismo derivado do cartesianismo moderno: o modelo

* Endereços para correspondência: mar.michel@gmail.com; fernando.andacht@fic.edu.uy de self dialógico e o modelo semiótico. A Teoria do Self Dialógico (doravante TSD) (Hermans \& Kempen, 1993; Hermans, 2001; Valsiner, 2005; Salgado \& Clegg, 2011) e A Teoria do Self Semiótico (doravante TSS) (Peirce 1931-58; Colapietro, 1989; Wiley, 1994) assumem que o desenvolvimento da identidade é o resultado de processos dialógicos internos. Apesar de serem modelos distintos, eles compartilham a influência teórica de pensadores do pragmatismo, como C. S. Peirce, W. James, e G. H. Mead. Alguns possíveis desdobramentos de uma síntese teórica dialógico-semiótica podem ser de interesse para se elaborar uma proposta alternativa para a psicologia a partir de um modelo comunicacional (Jardim, Souza, \& Gomes, 2009). Por outro lado, a complementaridade entre os modelos reside na ênfase que os dois depositam no aspecto temporal/desenvolvimento do self(SST) e na experiência espacial de um self não monológico (TSD) (Souza \& Gomes, 2009; Wiley, 2006; Raggatt, 2010; Lopes de Oliveira, 2012). Uma das tentativas de desenvolver um modelo que integra a semiótica triádica de Peirce com o modelo dialógico do self foi proposta por Raggatt (2010). O autor fundamenta-se no fato de que as duas teorias compartilham uma concepção que reúne uma multiplicidade de representações de identidade com um self integrado, que é uma realização progressiva e não uma entidade estática, preexistente. Segundo Raggatt (2010):

Há uma sinergia com a teoria do self dialógico (TSD), porque a multiplicidade é uma premissa fundamental na concepção dialógica do self. Ao mesmo tempo, porém, uma abordagem dialógica deveria ser capaz de explicar experiências de integração ou "tendências centralizadoras" na experiência do self. (p. 401) 
Raggatt (2010) postula “tríades dialógicas” (p. 408) para estudar o diálogo interno, através da integração de "descrições do self dialógico como sendo multiposicionado ou 'multivocal' (Hermans, 2001) e o papel dos 'objetos mediadores' como símbolos para a autorrepresentação" (p. 400).

Nosso objetivo neste trabalho é expor mais explicitamente algo que está implícito, mas não totalmente explorado por Raggatt, qual seja, a interrelação entre as três categorias fenomenológicas que estão na base da semiótica peirceana. Tentaremos argumentar sobre a relevância da tríade semiótica de C. S. Peirce para a construção de uma teoria dialógica baseada em princípios do realismo pós-positivista. Usaremos um exemplo extraído de uma pesquisa realizada na Universidade Federal do Rio Grande do Sul (Michel, 2006) focada no estudo do diálogo interno para ilustrar as possíveis aplicações analíticas do modelo triádico no marco da psicologia dialógica.

Nós acreditamos que há implicações clínicas importantes, possíveis de se extrair de uma teoria convergente de TSD e TSS, em especial se considerarmos as múltiplas atualizações do self, em constante mudança diante das circunstâncias sociais, enquanto posições/signos localizados, e sua relação sistêmica com a noção abrangente de self como um processo semiótico em desenvolvimento. Wiley (1994) afirma que há uma distorção patológica no processo de autointerpretação quando aspectos parciais do self - "identidades particulares" - ocultam sua totalidade. Nas lutas culturais pós-modernas, quando prevalecem identidades políticas, étnicas ou de gênero, ou quando traços pessoais, tais como os autoconceitos, acabam absorvendo o self e tornam-se "identidades invasivas, quase cancerígenas que dominam o self" (p. 38). Trata-se de um fenômeno que Wiley (1994) compara ao "falso-self" de Winnicott (1960) e ao narcisismo de Kohut (1971). Branco \& Freire (2012) argumentam contra uma perspectiva não processual, e elas afirmam que a TDS requer ferramentas metodológicas para estudar "concepções dinâmicas de si", uma noção que elas propõem "como uma alternativa dialógica às construções autorreferenciais tradicionais, tais como a autoestima, $\mathrm{o}$ autoconceito, etc. a fim de abordar o desenvolvimento do self dialógico" (p. 1).

\section{O self como processo dialógico e sígnico}

Dentro do marco da teoria do self dialógico, Salgado e Clegg (2011) afirmam que a influência de Bakhtin introduziu na psicologia o conceito de dialogismo, que permite recuperar a noção de psique assim como do self como metáfora válida para o estudo da identidade humana. $\mathrm{O}$ âmbito interno acabou sendo afastado dos estudos psicológicos nas teorias behavioristas, no materialismo biológico assim como no construccionismo social. Uma das principais contribuições da perspectiva dialógica, segundo os autores, é o principio da "relacionalidade", que permite fugir das classificações da "experiência humana em termos de substâncias ou entidades” (p.428 8).
Paralelamente, no marco da teoria semiótica, Wiley (1994, pp. 145-166) afirma que uma consequência da radicalização das posturas clássicas é a dificuldade de explicar satisfatoriamente o ser humano sem reduzi-lo a alguma outra realidade. O resultado seria o esvaziamento da noção de self, que perde o seu significado específico, ora restringido ao funcionamento da inteligência artificial ou da biologia molecular - uma estratégia que é descrita como "reducionismo descendente" - ora reduzido a convenções sociais na teoria social francesa pós-estruturalista e pós-moderna. Este último tipo de reducionismo é reconhecido como "reducionismo ascendente". O estudo psicológico do ser humano requer a concepção do self um nível específico, em relação com os outros níveis organizacionais, quais sejam, os níveis cultural, social e biológico. Uma concepção semiótica baseia a agentividade do sujeito na sua capacidade interpretativa. Isso não supõe o desconhecimento nem de sua natureza social nem do organismo, porque a autoconsciência é uma realização de um processo interpretativo, através do qual o self emerge como um signo pela própria condição da consciência de ser uma "consciência encarnada" e imersa numa rede de relações (Colapietro, 1989, p. 69).

A proposição do modelo do self semiótico origina-se em um trabalho de compilação crítica realizado por Colapietro (1989), de todas as referências à noção do self espalhadas na extensa obra de Peirce. O objetivo era estabelecer as bases para uma teoria semiótica do desenvolvimento da identidade. Na sua condição semiótica, a natureza humana é caracterizada pela capacidade de gerar signos cada vez mais desenvolvidos (interpretantes), e pelo processo autocontrolado de conhecimento de si. A principal tese do trabalho de Colapietro, (1989, p. 61) é que a visão de Peirce a respeito do self não tem sido adequadamente apreciada na história, por não ter sido considerada em uma perspectiva desenvolvimental. $\mathrm{O}$ intuito fundamental é assim salientar que, na perspectiva semiótica, o self é concebido como um signo que está sempre "no processo de virar um self, um processo que nunca está terminado completamente" (Colapietro, 1989, p. 77). Isso é compatível, consideramos, com o objetivo da TSD de resolver o dilema aparente entre a noção de um self centralizado e uma multiplicidade desintegrada através da consideração do "conceito do self como um construto desenvolvimental" (Lopes de Oliveira, 2012).

$\mathrm{O}$ autoconhecimento é um processo dialógico. $\mathrm{O}$ diálogo significa um limite eficaz à onipotência do indivíduo. Somente se aceitarmos os limites que nossa condição semiótica impõe ao controle da identidade individual é possível realizar plenamente nosso poder semiótico. Isso implica uma capitulação, uma entrega do eu como dono de sentido. A capacidade semiótica não permite atribuir de modo arbitrário o sentido às coisas ou aos semelhantes. O self, entretanto, sendo objeto interpretado não é nada além de outro signo no multiforme e cambiante universo semiótico. Nele, o sentido progride da mesma maneira que uma conversação que precede a cada ser individual e que 
continua mesmo depois de sua morte. Concomitantemente, a natureza semiótica habilita os seres humanos a participar dessa contínua semiose universal e do processo de crescimento da razoabilidade universal. A outra face do diálogo é possibilitar uma grande oportunidade. Enquanto signos, mediadores do sentido, os seres humanos participam tanto do mundo mecânico de forças físicas quanto do entendimento das relações entre elas.

\section{A fenomenologia triádica e o self dialógico}

Embora haja vários pontos de contato entre a teoria semiótica pragmática e as teorias pós-modernas derivadas do pensamento historicista de G. Vico (1744), cujo princípio epistemológico é que "saber é fazer e fazer é saber" (Hermans, 2003, p. 91), há uma diferença entre elas. A semiótica propõe que nosso conhecimento deriva dos signos, da mediação do real, mas esse conhecimento não constrói totalmente o real, sua função consiste em representá-lo: os signos são uma forma imprescindível de acesso ao real. Nosso modo de acesso ao universo é parcial e imperfeito, uma vez que ele é a um tempo, direto (experiência sensorial) e também mediado por signos no entendimento (Ransdell, 1977). Outra diferença é que o conceito de signo não se reduz aos signos usados na linguagem verbal, seja oral ou escrita. Sem nunca afirmar que tudo o que há no mundo é somente semiótico ou feito de signos, nem que o universo só deveria ser considerado como signo, a semiótica pragmática propõe que qualquer coisa no mundo pode ser considerada enquanto signo, se existir algum interesse em analisá-la dessa perspectiva. Na semiótica triádica, o conceito de signo é inseparável do conceito de processo da ação dos signos ou semiose.

$\mathrm{O}$ termo semiose indica que o assunto estudado pela teoria não é meramente o signo, nem sequer o conjunto deles, mas o processo de sentido, a geração de efeitos de sentido. A semiótica considera a capacidade de ação dos signos para gerar outros signos (chamados interpretantes) e são eles signos mais desenvolvidos ou complexos, aqueles que manifestam o significado (do objeto semiótico, de aquilo que é representado). $\mathrm{O}$ pensamento é concebido como um processo semiótico que evolui e desenvolve-se como resultado da relação de representação triádica entre os elementos lógicos que definem a mediação sígnica, a saber, o signo (chamado também representamen), o objeto e o interpretante. Segundo Peirce:

Um representamen é o sujeito de uma relação triádica com um segundo, chamado seu objeto, para um terceiro, chamado seu interpretante, essa relação triádica é tal que o representamen determina seu interpretante para manter a mesma relação triádica com o mesmo objeto para algum interpretante. (CP 1.541, grifos do autor)

A semiótica baseia-se em uma faneroscopia, isto é, em uma forma de fenomenologia que foi assim denominada para marcar a diferença com a fenomenologia do espírito de Hegel. Para Peirce, o conhecimento de todo fenômeno, tanto natural quanto cultural, envolve analiticamente três categorias da experiência, chamadas de Primeiridade, Secundidade e Terceiridade. A categoria da Terceiridade pressupõe as outras duas por referir-se à cognição. As outras duas categorias só podem ser consideradas cognitivamente se assumirmos uma postura analítica diante da nossa própria experiência. A Primeiridade é a categoria da indeterminação; ela caracteriza-se pela infinita multiplicidade de possibilidades qualitativas. A Secundidade implica a interação diádica de um ego perante um não ego (CP 1.325). Mas essas duas categorias só podem ser pensadas ou compreendidas na Terceiridade, que explica analiticamente a cognição, por ser esta a faculdade que gera regularidades, e para isso implica a mediação dos signos.

Desse modo, a semiótica de Peirce opera com uma estrutura triádica do signo, constituída por um signo, um objeto e um interpretante em constante desenvolvimento. Esse processo é essencialmente dialógico porque a natureza do interpretante é sígnica e, portanto, ele vai gerar uma nova resposta em um outro signo interpretante, que será ainda mais complexo, como o que acontece no diálogo humano: cada intervenção gera uma elaboração que traz consigo maior complexidade discursiva. Nesse aspecto há uma marcante afinidade com uma das fontes da TDS, qual seja, a "ação interlocutiva" de Bakhtin (1986): o fato de toda enunciação estar "dirigida a alguém" (p. 95) faz que ela inclua o outro na sua própria gênese.

Peirce (CP 7.551) descreveu uma correspondência entre as categorias e três modalidades de consciência: a Primeiridade corresponde à consciência imediata de um sentimento (feeling), enquanto conteúdo da consciência no momento presente em seu aspecto qualitativo mais simples e absoluto sem ser atribuído a nenhum sujeito nem a nada em particular; a Secundidade corresponde à consciência de algo externo diretamente presente através das sensações de ação e reação, de esforço e resistência; e a Terceiridade corresponde à consciência sintética da mediação que caracteriza o entendimento da relação através do pensamento. Em termos psicológicos, as três modalidades correspondem a sentimento, volição e cognição, respectivamente.

A correspondência entre as modalidades da consciência e os componentes do signo constitui a base de um processo autointerpretativo que se desenvolve a partir de uma convergência ou relação entre três elementos, como pode-se observar na Figura 1.

Na categoria da Secundidade encontra-se o objeto semiótico, que corresponde ao aspecto existencial do signo, isto é, enquanto uma coisa que existe no mundo além da vontade de quem tem uma experiência. O objeto semiótico não é necessariamente aquilo que possui materialidade. Sua existência se manifesta no limite que impõe uma força, por ser algo não criado pela mente, por manifestar uma "autovontade" (self-willedness, CP 7.488). Trata-se de "relações, isto é, fatos de Secundidade, tal como a percussão resultante da batida da pedra no chão, quando o esforço 
da pedra contra a resistência do solo resulta em polaridade bruta" (Santaella, 1999). Portanto, essa categoria implica a interação diádica de um ego diante de um não ego (CP 1.325), considerada somente em seu aspecto reativo, sem considerar o pensamento.

A categoria da Terceiridade refere-se ao significado como um efeito de sentido, isto é, o "interpretante" do signo triádico. O significado, porém, não é atribuído ao signo pela ação de uma mente. Ao contrário, ele faz parte do signo como uma interpretação possível, o chamado interpretante imediato, que refere-se a um sentido plausível do signo, sem que seja necessário que alguma pessoa haja interpretado efetivamente o signo. Por outra parte, Peirce chamou de interpretante dinâmico "qualquer interpretação que alguma mente concretamente faz de um signo" (CP 8.315).

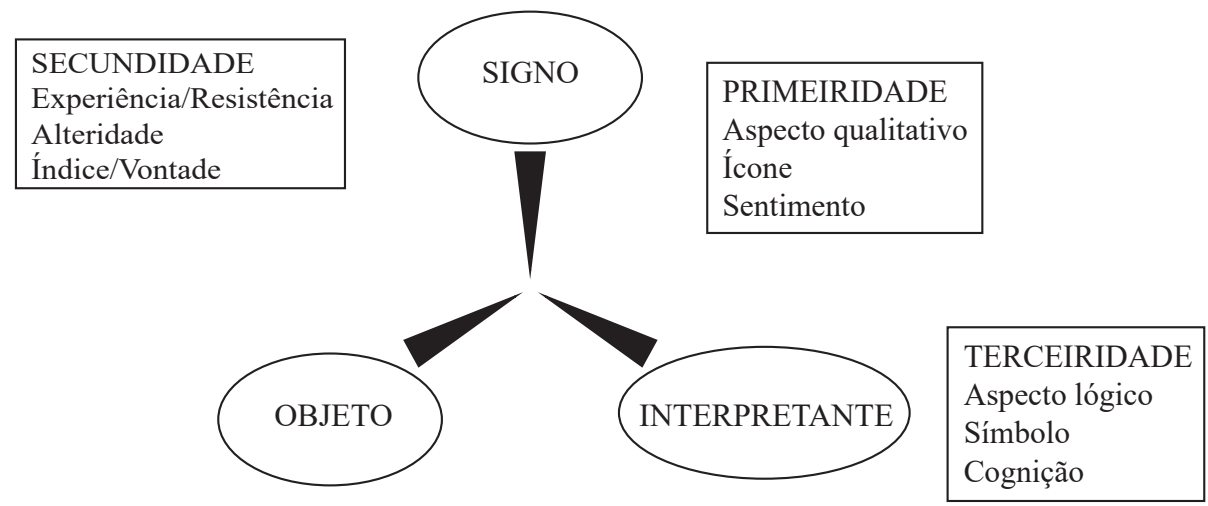

Figura 1. As categorias fenomenológicas da experiência como base do processo autointerpretativo

\section{O dialogismo na semiótica triádica como base da convergência teórica}

Com a ênfase na comunicação e a interação em estudos de psicologia de identidade, a mediação semiótica tem se tornado cada vez mais relevante para esse campo. Branco e Valsiner (1997), Hermans (1996), Lopes de Oliveira (2012), Simão (2005), Souza, Silveira e Gomes (2008), Souza e Gomes (2009) e Valsiner $(2002,2005,2007)$ salientam a complementaridade entre o elemento temporal no modelo semiótico do self e a ênfase espacial na TSD - por exemplo "a estrutura espacial da mente" (Hermans, 2003, p. 93). Por outro lado, Valsiner (2005) propõe uma descrição do self dialógico como um self que se autorregula semioticamente (p. 202), além de incluir em outro trabalho a semiótica triádica de Peirce como uma das fontes teóricas do modelo dialógico (Valsiner, 2007, pp. 40-51). Isso abre um caminho para continuar explorando essa base teórica comum. Quando Valsiner (2007) cita a seguinte definição de signo de Peirce: "Um signo é um objeto que representa um outro para alguma mente" (1873/1986, citado em Valsiner, 2007, p. 40; grifos deste autor), ele salienta a natureza dialógica e orientada para o futuro dos processos sígnicos.

Como esse quadro das três categorias encarregadas de analisar a experiência pode se aplicar à convergência da TSD e TSS? Em um artigo clássico de Hermans (2003), há uma definição do self dialógico na qual se apontam três elementos principais com os quais vamos procurar estabelecer uma correspondência com as três categorias da TSS. Nele, o selfé definido como

uma multiplicidade dinâmica de posições do eu relativamente autônomas. Nesta concepção, o eu tem a capacidade de se deslocar de uma posição espacial para outra, de acordo com mudanças na situação e no tempo. $\mathrm{O}$ eu flutua entre posições diferentes e inclusive opostas, e possui a capacidade de dotar imaginativamente cada posição de uma voz para que possam ser estabelecidas relações dialógicas entre as posições. (p. 101)

O primeiro elemento da citação que vamos a considerar é o eu abstraído de qualquer posição concreta; trata-se de um eu que "flutua" entre múltiplas posições, e assim poderia ser interpretado semioticamente como uma instância da Primeiridade (CP 3.422): o eu caracterizado por ter "um elemento de indeterminação" (CP 6.13). Se considerarmos analiticamente o eu independente de qualquer posicionamento espaço-temporal, atendendo exclusivamente a seu poder de flutuar, o eu poderia ser concebido na sua espontaneidade, a qual remete à Primeiridade.

Um segundo elemento que vamos considerar, tomando por base a citação de Hermans, é o eu localizado em uma posição determinada. O posicionamento do eu pode ser concebido como pertencendo a uma categoria fenomenológica diferente, o da Secundidade. Por exemplo, quando o autor fala das "posições diferentes e . . o opostas", essa contraposição envolve uma relação diádica, um contraste entre dois elementos. Um dos termos usados por Peirce para descrever a categoria da Secundidade é "resistência" (CP 1.24), por exemplo, a que existe na oposição entre ego e não ego (CP 1.37). O eu localizado ou posicionado é um existente, por isso ocupa um determinado espaço e, portanto, gera resistência. A oposição entre ego e não ego produz "uma consciência de dupla face, de esforço e de resistência" (CP 1.24), algo que "não envolve a noção de tempo (ou seja, não de um 
continuum), mas envolve o sentido de ação e reação, resistência, externalidade, alteridade, ser um par" (CP 8.41).

Enquanto Hermans (2003) considera como parte do posicionamento do eu o espaço e também o tempo, na TSS a inclusão de temporalidade refere-se à categoria da Terceiridade, da generalidade, ou seja, da regularidade que nos permite prever futuros resultados. O terceiro elemento da citação de Hermans (2003), a voz, envolve a temporalidade. Trata-se do processo através do qual surge e desenvolve-se certa regularidade, que emerge das características de uma voz por meio da qual "podem ser estabelecidas relações dialógicas entre as posições” (p. 101). Portanto, a noção de voz da TSD equivale à Terceiridade, ao signo simbólico, porque funciona como uma regra: podemos prever como essa voz vai se manifestar de modo consistente com as características que a definem. Quando um processo funciona ao longo do tempo, isso significa que há um terceiro elemento envolvido, uma razão ou uma lei que o governa, que lhe dá um direcionamento, mediando entre os dois elementos da díade:

Se houvesse algum processo que intervém entre o ato de causalidade e o efeito, isso teria constituído um elemento mediador [medial], ou terceiro. A Terceiridade ... é o mesmo que a mediação. Por esse motivo, o diádico puro [dyadism] é um ato de vontade arbitrária ou de força cega; porque se houver alguma razão, ou lei, que o governasse, isso medeia entre os dois sujeitos e produz sua conexão. (CP 1.328)

Para resumir, a categoria da Primeiridade explica a plasticidade do eu flutuante, a da Secundidade as posições localizadas do eu, e a da Terceiridade a continuidade e a tendência à unidade do processo dialógico.

\section{Espacialidade e temporalidade no diálogo interno: 0 dilema de Martin}

Dois antecedentes no esforço por construir uma convergência entre a TSD e a TSS são Wiley (1994) e Raggatt (2010, 2014). As "tríades dialógicas" baseadas na Terceiridade, postuladas por Raggatt (2010) para "analisar o self dialógico" (p. 400), propõem que a temporalidade seja a manifestação dessa categoria, qual seja a mediação semiótica. Em tal sentido, há uma coincidência com nossa própria análise, que separa o tempo do espaço na aplicação das categorias peirceanas ao self dialógico. Não obstante, no modelo do self que vamos propor aqui há uma diferença no uso das categorias: enquanto Raggatt (2014, p. 110) separa as posições do eu opostas como sendo da Secundidade e da Terceiridade, nós propomos colocar essa oposição como parte da Secundidade. A justificação para essa análise do self é que a díade é o que define essa categoria: ela está composta por dois e só dois elementos contrapostos. Para compreender a relevância dessa análise vamos a apresentar e discutir brevemente um caso extraído da pesquisa de um dos autores deste artigo (Michel, 2006).
O exemplo foi extraído de uma pesquisa focada em estudar o diálogo interno e pode servir para ilustrar as implicações da análise triádica no estudo do self dialógico. Por outro lado, a ilustração pode também ajudar a esclarecer a relevância da distinção conceptual entre as noções de self e das posições do eu para o desenvolvimento psicológico da pessoa. O caso escolhido para a ilustração é a fala de um participante de 19 anos (que foi denominado "Martín") que, como parte da pesquisa, aceitou expressar em voz alta seus pensamentos relativos a uma dúvida ainda não resolvida sobre sua própria vida: mostrar-se ou não tal como ele é. O instrumento utilizado na pesquisa combinou duas técnicas psicodramáticas (Moreno, 1975): a Cadeira Vazia e os Aspectos Diferentes do Self(Blatner, 1995).

Uma vez designado um espaço como cenário, Martín começou a expressar seus pensamentos sob a forma de solilóquio, uma técnica psicodramática similar à utilizada no teatro. Tudo começou quando a mãe de Martín lhe perguntou se ele tinha um isqueiro para acender uma vela, "quando, de repente, falta luz". Ele tem dúvida entre dizer a verdade, que sim, ele tem, ou "esconder" isso. No momento em que dois argumentos contrários para sustentar uma e outra posição começaram a se manifestar, Martín (seguindo as instruções), colocou duas cadeiras para visualizar as opções. Martín sentou na cadeira $n^{0} 1$, que representava a posição "Martín criança", cada vez que falou sobre como ele "ainda faz coisas escondido e que tem medo de punição". Em contraposição, surgiu a posição "Martín revoltado": quando sua fala era interrompida por um argumento contraposto, Martín mudava para a cadeira $\mathrm{n}^{\mathrm{o}} 2$ e vice-versa. Inclusive, próximo do fim do diálogo, surgiu uma terceira posição, que ele mesmo chamou de "síntese dos dois". Apresentamos algumas frases de cada uma das posições do eu:

Posição Martín criança:

- Eu não tenho coragem de falar para meus pais que eu fumo... apesar deles fumarem os dois, eles nunca aprovariam que eu fumasse... e... e...não é só de meus pais que eu me escondo, também de minha namorada que também não deixa eu fumar porque eu fumo escondido...

- Aí que tá, eu me escondo e faço o bonzinho, "eu não fumo"... aí largo ela na casa e vou direto para casa fumar no banheiro, sabe? Escondido dela e de minha mãe.

Posição Martín revoltado:

- Eu acho que eles têm que me aceitar do jeito que eu sou, mas não me aceitam, se eu digo para minha namorada: "olha aqui, eu fumo e eu vou continuar fumando independente do que tu tá achando"... ela não quer um namorado fumante.

Posição Martín síntese:

- E esse Martín aqui, não sabe quê fazer, se se esconder ou se ficar revoltado... 
- Por isso para ter a liberdade, para poder assumir essa posição aqui, eu vou ter que ser mais aberto.

- Sim, eu acho que esse é um Martín sintese dos dois ... aqui está a briga: eu acho que as pessoas têm que ser autênticas, abertas, só que eu tenho medo enquanto que [sic] esse aqui faz as coisas às escondidas. (comunicação pessoal; Michel, 2006, pp. 263-265)

A utilidade das três categorias como uma possível contribuição para um modelo do self dialógico torna-se mais clara se analisarmos com elas o discurso do diálogo interno, seus movimentos. Por um lado, a categoria da Primeiridade serve para analisar os possíveis deslocamentos entre as diferentes posições do eu conforme a definição da categoria caracterizada pela indeterminação do Presente. Portanto, os possíveis movimentos do self são inúmeros, o que explica as variações do self. Porém, tais mudanças podem ser muito pequenas. As três categorias interagem permanentemente; nessa interação o indeterminado e os impactos do real externo fazem que a regularidade não seja fixa, rígida; evita-se assim o determinismo nesse modelo do self.

Por outro lado, a categoria da Secundidade explica o fato da existência das posições do eu opostas - criança vs. revoltado - e assim funciona como um limite do real perante a proliferação de infinitos possíveis, a Primeiridade. A existência dessas presenças discursivas de alteridade citadas no discurso de Martín - a desaprovação de seu comportamento por parte dos pais e da namorada - manifesta um limite externo, uma força opositora (Secundidade), uma "autovontade" (self-willedness, CP 7.488), que ele reconhece como impossível de modificar apenas com seu pensamento ou vontade. Assim como existe uma oposição entre as duas posições do eu, elas mesmas surgem como reação ao limite do real: a atitude de objeção dos pais e da namorada de Martín: "Eu acho que eles têm que me aceitar do jeito que eu sou, mas não me aceitam" (comunicação pessoal; Michel, 2006, p. 264).

Finalmente, a Terceiridade corresponde à posição meta do self - aquilo que o próprio Martín chama de "síntese" - e é o nascimento de uma tendência, de uma regularidade. Essa tendência é mais complexa, porque Martín vai nomear as vozes, i.e., usar conceitos para se compreender. A Terceiridade, ou mediação, justifica pensar no self como um signo em desenvolvimento, portanto a temporalidade é um componente essencial, o que impede de considerá-lo como algo terminado ou completo. A "síntese" supõe uma compreensão de que nenhuma das posições do eu esgota $o$ self enquanto processo, por isso Martín menciona o futuro, como o que vai lhe permitir se abrir a outros possíveis na sua vida.

Propomos agora o seguinte diagrama na Figura 2 para descrever a convergência do espacial e do temporal nas teorias dialógicas que vamos ilustrar com o caso citado a seguir:

Eu Flutuante/Primeiridade Possibilismo: movimento entre as cadeiras

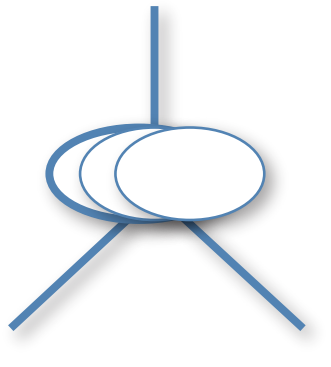

Pos. 1 \& Pos. 2/Secundidade

Relação Diádica

entre duas posições do eu

(conflito interno, "briga")

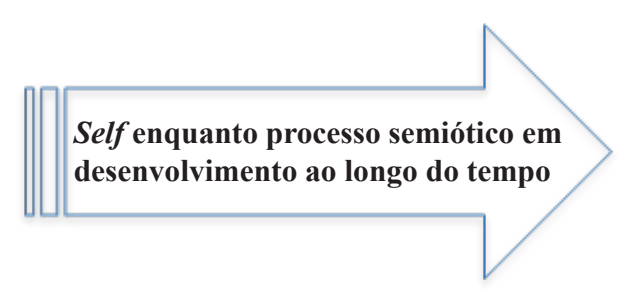

Interpretante (Self crítico)/Terceiridade

Vozes como regularidades ("criança"; "revoltado")

Mediação como síntese

Figura 2. Convergência dos modelos dialógicos

Do ponto de vista semiótico, cada uma das vozes de Martín é um interpretante dinâmico, ou seja, uma interpretação concreta que resulta do entendimento parcial que Martín possui sobre si mesmo em um momento preciso no tempo. Tais interpretantes são emergentes do processo autointerpretativo em relação a algumas circunstâncias particulares de sua vida, no marco das interações concretas com pessoas específicas (por exemplo seus pais, sua namorada). Se uma dessas identidades (criança ou revoltado) fosse considerada a única realidade do self, o verdadeiro self de Martín não estaria sendo adequadamente compreendido nem autocompreendido em sua processualidade. Assim, apareceria o risco do processo autointerpretativo ser bloqueado, levando ao fenômeno do falso-self. Contrariamente, a oposição dialógica no âmbito do seu próprio self permite a Martín perceber as duas posições como aspectos parciais do self. Na procura de uma resolução para o conflito interno, torna-se evidente o 
aspecto desenvolvimental do self, sendo os interpretantes dinâmicos apenas estágios transitórios.

O self crítico é um self autocrítico. O self não possui total controle do mundo interno, porque as vozes emergem na relação com outros (as pessoas diante das quais Martín procura ocultar seu hábito). As vozes são interpretantes, e seu significado não pode ser atribuído arbitrariamente por Martín. A capacidade de auto-observação permite orientar o processo visando um objetivo, o self crítico, o qual tem capacidade de autocontrole mas também percebe os limites do real, o que inclui o autoconhecimento: "eu acho que as pessoas têm que ser autênticas, abertas, só que eu tenho medo enquanto que esse aqui faz as coisas às escondidas" (comunicação pessoal; Michel, 2006, p. 265).

\section{Considerações finais}

A abordagem semiótica é compatível com o objetivo das perspectivas pós-modernas de explicar o descentramento do sujeito e com a crítica à indivisibilidade do individuo. O conceito de signo triádico, contrariamente ao construtivismo e ao contrucionismo - que se baseiam no estruturalismo -, abre um espaço teórico para incluir no âmbito intrapsicológico a influência da experiência e da alteridade nos processos interpretativos. A resistência da realidade externa opera no pensamento introduzindo a voz de um oponente dialógico. O conflito resultante, longe de ser um prejuízo para o desenvolvimento do self, atua como um motor para a reflexividade. Embora pareça um paradoxo, a divisão interna pode promover a integração de self num nível lógico superior, o qual favorece a auto-observação, o autocontrole e a unidade do self ao longo do tempo. O self crítico do diagrama prévio é uma identidade supraordenada: ela não se reduz a nenhuma das vozes em oposição dialógica.
Um desenvolvimento autocontrolado, que seja uma decorrência do livre arbítrio, depende não somente da vontade subjetiva, mas da interação dialógica com o limite estabelecido por outra vontade (alteridade), independente do desejo subjetivo. Desse modo, a autonomia ou livre arbítrio do self distingue-se da onipotência. Por esse motivo, é preciso substituir a noção semiológica-estruturalista da atribuição arbitrária de significados por uma semiótica que inclua um vínculo necessário com o âmbito externo à representação. Uma das causas da confusão entre a noção do self $\mathrm{e}$ as posições do eu estaria relacionada à incapacidade de se aceitar o efeito de sentido produzido pela presença obstinada da alteridade na constituição do si próprio e, consequentemente, a dificuldade para tolerar a autocontradição no mundo interno.

A definição de alteridade como resistência (Secundidade, no sentido peirceano), assim como a consideração dos efeitos positivos do antagonismo dialógico, além da distinção analítica da temporalidade, que faz parte da categoria da Terceiridade, são algumas das principais conclusões deste trabalho no que diz respeito à convergência entre os dois modelos, a TSD e a TSS. Também é importante a reflexão sobre o elemento que introduz a possibilidade do novo no processo do self, qual seja, a categoria da Primeiridade.

Uma visão ampliada do signo, que nos permite considerar o self como signo em desenvolvimento dialógico poderia restabelecer a relevância da significação polifônica, mais próxima da rica pluralidade sensorial de uma orquestra do que de uma solitária voz isolada e estática, para assim conseguir nos adaptar e desenvolver com sucesso no mundo circundante, que jamais cessa de mudar desde o nascimento até a morte, e que por isso, tem que ser abordado como um caleidoscópio de signos em contínua mudança, cuja complexidade não deixa de crescer.

\title{
Steps to a convergence of two dialogical theories of the self
}

\begin{abstract}
In this paper, we aim to describe the elements that would enable researchers to bring together two different but complementary theories of the self in the dialogical psychology field: the theory of the semiotic self, based on C. S. Peirce's triadic model of meaning generation, and the theory of the dialogical self, based on the work of $\mathrm{H}$. Hermans, which derives from M. Bakhtin's and W. James's reflections on dialogism. The benefit of this theoretical convergence is argued through a discussion of the structural elements of triadic semiotic, including its phenomenological basis and its kinship with key concepts of the Dialogical Self Theory. We also present a case in which the internal dialogue of a person who has an important doubt regarding his life is observed through a psychodramatic method, and the posited theoretical convergence of dialogical theories is illustrated through the manifestation of opposite I-positions. Throughout the dialogue an attempt of synthesis through the emergence of a meta-position was observed.
\end{abstract}

Keywords: semiotic self, dialogical self, theoretical convergence, internal dialogue.

\section{Vers une convergence de deux théories dialogiques du soi}

Résumé: Dans cet article, notre but est de décrire certains éléments qui donnent la possibilité aux chercheurs de rapprocher deux théories différents, mais complémentaires du soi dans le champ de la psychologie dialogique: la théorie du soi sémiotique - basée sur le modèle triadique de la génération de sens de C. S. Peirce, et la théorie du soi dialogique - proposée dans les 
travaux de H. Hermans, qui pour sa part dérivent des idées du dialogisme de M. Bakhtin et de W. James. Le bénéfice de cette convergence théorique est justifié à travers la présentation des composantes structurales de la sémiotique triadique, en incluant sa base phénoménologique et son affinité avec les notions centrales de la théorie du soi dialogique. On discute un cas dans lequel le dialogue interne d'une personne qui a un doute important sur sa vie est observé sous la méthode psychodramatique, et ainsi la convergence théorique proposée est illustrée à travers la manifestation des positions de moi opposées et d'une tentative de synthèse à travers une méta-position.

Mots-clés: soi sémiotique, soi dialogique, convergence théorique, dialogue interne.

\section{Pasos para una convergencia de dos teorías dialógicas del self}

Resumen: En este artículo, se describen algunos elementos que harían posible que los investigadores reúnan dos teorías diferentes, pero complementarias, del self en el campo de la psicología dialógica: la teoría del self semiótico -basada en el modelo triádico de la generación de sentido de Peirce y la teoría del self dialógico- basada en los trabajos de Hermans, los que derivan del dialogismo de Bakhtin y de James. El beneficio de esta convergencia teórica es justificado a través de la presentación de los componentes estructurales de la semiótica triádica, incluida su base fenomenológica, y su afinidad con los conceptos centrales de la teoría del self dialógico. Consideramos un caso en el cual el diálogo interno de una persona con una duda importante sobre su vida es observado a través de un método psicodramático, y así la convergencia teórica propuesta es ilustrada mediante la manifestación de posiciones opuestas del yo. Se observó una tentativa de síntesis a través del surgimiento de una meta-posición.

Palabras clave: self semiótico, self dialógico, convergencia teórica, diálogo interno.

\section{Referências}

Bakhtin, M. (1986). Speech genres and other late essays. (V. W. McGee, trad.), Austin, TX: University of Texas Press. (Trabalho original publicado em 1961)

Blatner, A. (1995). Psychodramatic methods in psychotherapy. Psychiatric Times, 12(5), 20.

Branco, A., \& Valsiner, J. (1997). Changing methodologies: a co-constructivist study of goal orientations in social interactions. Psychology and Developing Societies, 9(1), 35-64.

Branco, A., \& Freire, S. (2012). Dynamic self conceptions: new perspectives to study children's dialogical self development. Paper presented at the $6^{\text {th }}$ Dialogical Self Conference, Athens, Greece.

Colapietro, V. (1989). Peirce's approach to the Self. A semiotic perspective on human subjectivity. Albany: State University of New York Press.

Held, B. S. (2007). Psychology's interpretive turn: the search for truth and agency in theoretical and philosophical psychology. New York, NY: American Psychological Association.

Hermans, H. (1996). Voicing the self: from information processing to dialogical Interchange. Psychological Bulletin, 11(1), 31-50.

Hermans, H. (2001). The dialogical self: toward a theory of personal and cultural positioning. Culture Psychology, 7(3), 243-281.

Hermans, H. (2003). The construction and reconstruction of a dialogical self. Journal of Constructivist Psychology, 16(2), 89-130.
Hermans, H. (2004). The dialogical self: between exchange and power. In H. Hermans \& Dimaggio, G. (Eds.). The dialogical self in psychotherapy (pp. 13-28). East Sussex, UK: Brunner-Routledge.

Hermans, H., \& Kempen, H. (1993). The dialogical self: meaning as movement. San Diego, CA: Academic Press.

James, W. (1892). The stream of consciousness. In Psychology, Chapter XI. Recuperado de http:// psychclassics.yorku.ca/James/jimmy11.htm

Jardim, A., Souza, M. L. de, \& Gomes, W. (2009). O self dialógico e a psicoterapia: uma compreensão dialógica da relação terapeuta-paciente. Contextos Clínicos, 2(1), 1-10.

Kohut, H. (1971). The analysis of the self. Chicago: The University of Chicago Press.

Lopes de Oliveira, M. C. S. (2012). The Bakhtinian self and beyond: towards a dialogical phenomenology of the self. Trabalho apresentado no $14^{\circ}$ Simpósio ANPEPP, Belo Horizonte, Minas Gerais, Brasil.

Michel, M. (2006). O self semiótico: desenvolvimento interpretativo da identidade como processo dramático. (Tese de doutoramento não publicada). Universidade Federal do Rio Grande do Sul, Brasil. Recuperado de http://hdl.handle.net/10183/7783

Moreno, J. L. (1975). Psicodrama. (D. Wagner, trad.) Buenos Aires: Ediciones Hormé. (Trabalho original publicado em 1946)

Peirce, C. S. (1931-58). Collected papers of C. S. Peirce: Vol. I-VIII. C. Hartshorne, P. Weiss \& A. Burks (Eds.). Cambridge, MA: Harvard University Press. 
Peirce, C. S. (1986). On the nature of signs. C. J. W. Kloesel (Ed.), Writings of Charles S. Peirce: a chronological edition (Vol. 3, pp. 66-68). Bloomington, IN: Indiana University Press. (Trabalho original publicado em 1873)

Praetorius, N. (2003). Inconsistencies in the assumptions of constructivism and naturalism: an alternative view. Theory \& Psychology, 13(4), 511-540.

Raggatt, P. (2010). The dialogical self and thirdness: a semiotic approach to positioning using dialogical triads. Theory \& Psychology, 20(3), 400-419.

Raggatt, P. (2014). The dialogical self as a time-space matrix: Personal chronotopes and ambiguous signifiers. New Ideas in Psychology 32, 107-114

Ransdell, J. (1977). Some leading ideas of Peirce's semiotic. Semiotica, 19(3/4), 157-178.

Salgado, J., \& Clegg, J. (2011). Dialogism and the psyche: Bakhtin and contemporary psychology. Culture \& Psychology, 17(4), 421-440.

Santaella, L. (1999). A new causality for the understanding of the living. Semiotica, 127(1/4), 497-519.

Simão, L. (2005). Bildung, culture and self: a possible dialogue with Gadamer, Boesch and Valsiner? Theory \& Psychology, 15(4), 549-574.

Souza, M. L. (2005). Self semiótico e self dialógico: um estudo do processo reflexivo da consciência (Tese de doutoramento não publicada). Universidade Federal do Rio Grande do Sul, Porto Alegre, Brasil. Recuperada de http://hdl.handle.net/10183/5566

Souza, M. L., da Silveira, A., \& Gomes, W. (2008). Verbalized inner speech \& the expressiveness of self-consciousness. Qualitative Research in Psychology, 5(2), 154-170.
Souza, M. L., \& Gomes, W. (2009). Temporalidade e espacialidade na estrutura do self nas abordagens semiótica e dialógica. Psicologia em Estudo, 14(2), 365373.

Valsiner, J. (2002). Forms of dialogical relations and semiotic autoregulation within the self. Theory \& Psychology, 12(2), 251-265.

Valsiner, J. (2005). Scaffolding within the structure of dialogical self: hierarchical dynamics of semiotic mediation. New Ideas in Psychology, 23(3), 197-206.

Valsiner, J. (2007). Culture in minds and societies: foundations of cultural psychology. New Delhi, India: SAGE.

Wiley, N. (1994). The semiotic self. Chicago: University of Chicago Press.

Wiley, N. (2006). Pragmatism and the dialogical self. International Journal for Dialogical Science, 1(1), 5-21.

Winnicott, D. W. (1960). Ego distortions in terms of true and false self in the maturational process and the facilitating environment. In M. Masud R. Khan (Ed.), The maturational process and the facilitating environment: studies in the theory of emotional development (pp. 140152). London, UK: Hogarth Press.

Recebido: 20/01/2015

Revisado: 22/03/2016

Aceito: 26/04/2016 